Article

\title{
Serological Evidence of Anaplasma phagocytophilum and Spotted Fever Group Rickettsia spp. Exposure in Horses from Central Italy
}

\author{
Valentina Virginia Ebani ${ }^{1,2}$ \\ 1 Department of Veterinary Science, University of Pisa, viale delle Piagge 2, 56124 Pisa, Italy; \\ valentina.virginia.ebani@unipi.it \\ 2 CIRSEC, Center for Climatic Change Impact, University of Pisa, via del Borghetto 80, 56124 Pisa, Italy
}

Received: 22 May 2019; Accepted: 24 June 2019; Published: 26 June 2019

check for updates

\begin{abstract}
Anaplasma phagocytophilum and Rickettsia spp. are tick-borne bacteria of veterinary and human concern. In view of the One-Health concept, the present study wanted to evaluate the spreading of these pathogens in horses living in central Italy. In particular, the aim of the investigation was to verify the exposure to $A$. phagocytophilum in order to update the prevalence of this pathogen in the equine population from this area, and to spotted fever group (SFG) Rickettsia spp. to evaluate a possible role of horses in the epidemiology of rickettsiosis. Indirect immunofluorescent assay was carried out to detect antibodies against A. phagocytophilum and SFG (spotted fever group) Rickettsia spp. in blood serum samples collected from 479 grazing horses living in central Italy during the period from 2013 to 2018. One hundred and nine (22.75\%) horses were positive for A. phagocytophilum, 72 (15.03\%) for SFG Rickettsia spp., and 19 (3.96\%) for both antigens. The obtained results confirm the occurrence of $A$. phagocytophilum in equine populations, and also suggest the involvement of horses in the epidemiology of SFG rickettsiosis. In both cases, in view of the zoonotic aspect of these pathogens and the frequent contact between horses and humans, the monitoring of equine populations could be useful for indication about the spreading of the tick-borne pathogens in a certain geographic area.
\end{abstract}

Keywords: horses; Anaplasma phagocytophilum; spotted fever group Rickettsia spp.; zoonosis; tick-borne infections

\section{Introduction}

Hematophagous arthropods, especially ticks, are well-known as vectors of several bacterial, viral, and protozoan pathogens. Among them, Anaplasma phagocytophilum and Rickettsia spp. may induce clinical manifestations in humans and different animal species.

Anaplasma phagocytophilum is an obligate intracellular, Gram negative bacterium belonging to the order Rickettsiales, family Anaplasmataceae. It is able to infect granulocytes, mainly neutrophils, of several domestic and wild animal species [1].

Wild mammals usually serve as asymptomatic reservoirs of $A$. phagocytophilum, whereas domestic animals may develop clinically defined diseases, such as tick-borne fever in cattle and sheep and granulocytic anaplasmosis in dogs [2]. Furthermore, A. phagocytophilum is cause of infection in human beings, who develop a disease called human granulocytic anaplasmosis (HGA), varying from mild to severe forms with fever, headache, myalgia, arthralgia, leukopenia, and thrombocytopenia; moreover, serious opportunistic infections can occur in immunocompromised patients during the course of HGA [3]. 
Horses infected by this pathogen develop a disease known as equine granulocytic anaplasmosis (EGA) (formerly equine granulocytic ehrlichiosis), characterized by a wide range of clinical signs. Usually, infected horses show fever, lethargy, ataxia, reluctance to move, icterus, and petechiation; laboratory blood abnormalities may include leukopenia, thrombocytopenia, and anemia [4].

In all animal species, A. phagocytophilum is transmitted by a tick bite. Ixodes species are involved in the epidemiology of this pathogen worldwide, in particular I. ricinus in Europe, including Italy [2].

The genus Rickettsia comprises obligate intracellular, Gram-negative bacteria transmitted by hematophagous arthropods. Spotted fever group (SFG) includes several Rickettsia species responsible for disease, often serious, in animals and humans. Rickettsia conorii is the etiologic agent of the Mediterranean spotted fever (MSF) that represents the most widespread SFG rickettiosis in the Mediterranean countries, including Italy, especially in the southern (Sardinia, Sicily, Calabria) and central regions [5], where most cases have been reported mainly between the months of June and September [6].

In Italy, several SFG rickettsiae are circulating, as mainly demonstrated by molecular investigations on tick populations. In particular, DNA of $R$. conorii, $R$. helvetica, $R$. massiliae, $R$. slovaca, $R$. monacensis, $R$. aeschlimannii, R. raoultii, and R. africae have been detected [7-12].

No data about the spreading of rickettsiae among horses living in Italy is available, and very scant information about equine rickettsiosis in other countries is present in the scientific literature [13,14].

Considering that anaplasmosis and rickettsiosis are zoonotic infections and the high occasion of contact between humans and horses, in view of the One-Health concept, the present study wanted to evaluate the spreading of these pathogens in horses living in central Italy. In particular, the aim of the investigation was to verify the exposure to A. phagocytophilum in order to update the prevalence of this pathogen in equine population from this area, and to SFG Rickettsia spp., to evaluate a possible role of horses in the epidemiology of rickettsiosis.

\section{Results}

Among the 479 tested horses, 109 resulted positive for A. phagocytophilum, with $22.75 \%$ total mean seroprevalence; prevalence values observed in the different years varied from $17.46 \%$ (2013) to $27.08 \%$ (2018). Antibody titers ranged from 1:40 to 1:1280.

Seventy two (15.03\%) horses had antibodies to SFG Rickettsia spp. Prevalence values ranged from $11.26 \%$ (2016) to $17.71 \%$ (2018) in relation with the years of sampling. Furthermore, antibody titers from 1:64 to 1:1024 were observed. Nineteen $(3.96 \%)$ horses had antibodies to both A. phagocytophilum and SFG Rickettsia spp. Results are summarized in Tables 1-3.

Table 1. Results obtained by indirect immunofluorescence test for Anaplasma phagocytophilum in relation to years of sampling and antibody titers.

\begin{tabular}{ccccccccc}
\hline \multirow{2}{*}{ Years } & \multirow{2}{*}{$\begin{array}{c}\text { N. Tested } \\
\text { Horses }\end{array}$} & $\begin{array}{c}\text { N. Positive } \\
\text { (\%) Horses }\end{array}$ & $\mathbf{1 : 4 0}$ & $\mathbf{1 : 8 0}$ & $\mathbf{1 : 1 6 0}$ & $\mathbf{1 : 3 2 0}$ & $\mathbf{1 : 6 4 0}$ & $\mathbf{1 : 1 2 8 0}$ \\
\cline { 4 - 9 } & 63 & $11(17.46)$ & 2 & 7 & 1 & 1 & - & - \\
2013 & 76 & $15(19.73)$ & 3 & 8 & 3 & - & 1 & - \\
2014 & 92 & $22(23.91)$ & 5 & 13 & 2 & 1 & - & 1 \\
2015 & 71 & $14(19.71)$ & 3 & 8 & 1 & 2 & - & - \\
2017 & 81 & $21(25.92)$ & 4 & 15 & 1 & - & - & 1 \\
2018 & 96 & $26(27.08)$ & 7 & 11 & 5 & 1 & 2 & - \\
Total & 479 & $109(22.75)$ & $24(5.01)$ & $62(12.94)$ & $13(2.71)$ & $5(1.04)$ & $3(0.63)$ & $2(0.42)$ \\
\hline
\end{tabular}


Table 2. Results obtained by indirect immunofluorescence test for spotted fever group (SFG) Rickettsia spp. in relation to years of sampling and antibody titers.

\begin{tabular}{cccccccc}
\hline \multirow{2}{*}{ Years } & \multirow{2}{*}{$\begin{array}{c}\text { N. Tested } \\
\text { Horses }\end{array}$} & \multirow{2}{*}{$\begin{array}{c}\text { N. Positive } \\
\text { (\%) Horses }\end{array}$} & $\mathbf{1 : 6 4}$ & $\mathbf{1 : 1 2 8}$ & $\mathbf{1 : 2 5 6}$ & $\mathbf{1 : 5 1 2}$ & $\mathbf{1 : 1 0 2 4}$ \\
\cline { 4 - 8 } & 63 & $9(14.28)$ & 5 & 3 & - & 1 & - \\
2013 & 76 & $13(17.10)$ & 4 & 5 & 3 & - & 1 \\
2014 & 92 & $11(11.95)$ & 6 & 5 & - & - & - \\
2015 & 71 & $8(11.26)$ & 3 & 3 & 2 & - & - \\
2016 & 81 & $14(17.28)$ & 4 & 2 & 5 & 3 & 1 \\
2017 & 96 & $17(17.71)$ & 8 & 6 & 2 & - & 1 \\
2018 & & $72(15.03 \%)$ & $30(6.26)$ & $24(5.01)$ & $12(2.50)$ & $4(0.84)$ & $2(0.42)$ \\
Total & 479 & & & & & & \\
\hline
\end{tabular}

Table 3. Horses resulted positive to both Anaplasma phagocytophilum and SFG Rickettsia spp. with indirect immunofluorescence test.

\begin{tabular}{ccc}
\hline Horses & Anaplasma phagocytophilum & SFG Rickettsia spp. \\
\hline 1 & $1: 80$ & $1: 64$ \\
2 & $1: 80$ & $1: 64$ \\
3 & $1: 80$ & $1: 128$ \\
4 & $1: 40$ & $1: 64$ \\
5 & $1: 160$ & $1: 64$ \\
6 & $1: 40$ & $1: 256$ \\
7 & $1: 80$ & $1: 128$ \\
8 & $1: 160$ & $1: 128$ \\
9 & $1: 80$ & $1: 128$ \\
10 & $1: 80$ & $1: 64$ \\
11 & $1: 80$ & $1: 64$ \\
12 & $1: 80$ & $1: 128$ \\
13 & $1: 40$ & $1: 128$ \\
14 & $1: 40$ & $1: 64$ \\
15 & $1: 320$ & $1: 64$ \\
16 & $1: 40$ & $1: 64$ \\
17 & $1: 40$ & $1: 256$ \\
18 & $1: 80$ & $1: 128$ \\
19 & $1: 80$ & $1: 64$ \\
\hline
\end{tabular}

\section{Discussion}

Tick-borne diseases are major animal and human health issues in several geographic areas. Global warming has deeply influenced the spread of hematophagous arthropods, including ticks, but other factors are involved in their distribution. Animals' movements, agricultural and wildlife management, and urbanization with consequent reduction of natural areas have determined changes in tick distribution, with increasing presence in urban and peri-urban environment.

Horses examined in this study lived in areas with environmental conditions which favor tick diffusion, especially abundant vegetation and presence of other animal species, mainly wildlife. Several tick species are present in this area, including Ixodes ricinus, which is the main vector of A. phaocytophilum [2] and is also involved in the transmission of rickettiae. Furthermore, the brown dog tick Rhipicephalus sanguineus, the main vector of $R$. conori, may be found not only among dogs, but also in wildlife [15].

Results obtained during this survey showed that the examined horses had been exposed to the investigated tick-borne pathogens, with a higher seroprevalence detected for A. phagocytophilum than for SFG Rickettsia spp. Higher values of seroprevalence for both pathogens were detected among samples collected in 2017 and 2018. These results could be related to climatic conditions that allowed a higher presence of ticks in the areas where the tested horses lived. However, the spread of arthropods is 
related to further factors (presence of other animals, environmental management, acaricide treatments) that were not fully known in this study.

Previous investigations found A. phagocytophilum infection in equine populations in Italy: in detail, serological surveys detected prevalence values ranging between $9 \%$ and $17 \%$, whereas molecular studies found prevalences from $4.7 \%$ to $25.62 \%$ [16-20]. Seroprevalences found in Europe, which ranged from $11.3 \%$ to $20 \%$, were quite similar [21-23]; conversely, molecular surveys carried out in some European countries detected lower prevalences that varied from $1.4 \%$ to $9.8 \%$ [24-26].

Furthermore, A. phagocytophilum infection was detected in other animal species living in Italy [27-30], as well as A. phagocytophilum DNA being found in ticks collected from animals or environment [31]. The present results confirm the spreading of this tick-borne pathogen among equine populations in the investigated areas. Moreover, considering that the tested animals did not show clinical signs, the results corroborated that asymptomatic forms may be developed by infected horses. In fact, some authors affirm that horses from endemic areas have a higher seroprevalence to A. phagocytophilum than those from non-endemic areas, and horses introduced into an endemic area are more likely to develop illness than native horses [32]. However, clinical findings, when present, are not specific, and it can be difficult to differentiate EGA from other diseases, mainly piroplasmosis. Moreover, horses infected by A. phagocytophilum are predisposed to developing secondary infections, which may complicate the clinical diagnosis [32].

Data about the presence of SFG Rickettsia spp. in Italy mainly concern humans [33]. Some studies have been carried out in ticks and wild animals, and case reports of canine rickettsiosis have also been documented [34,35]. Data about rickettiosis in Italian equine populations are not available in the scientific literature, and very scant studies have been reported from other European countries. Elfving et al. [13] tested sera from 63 horses in Sweden with indirect immunofluorescence assay (IFA) employing R. helvetica as antigen, and found a 36.5\% prevalence; Skotarczack et al. [14] found $R$. helvetica and R. monacensis DNA in two ticks collected from ponies in Poland.

Furthermore, serological surveys have been carried out in horses living in South America. A 2.85\% seroprevalence for SFG Rickettsia spp. was found in horses from Colombian Orinoquia [36]; in Brazil, 183/504 (36.3\%) horses were seropositive for Rickettsia rickettsii [37], whereas among 258 horses tested for $R$. rickettsii, $R$. amblyommatis, and R. bellii, 152 (58.91\%) were seroreactive for at least one Rickettsia species [38].

To the best of our knowledge, this is the first serological survey on the occurrence of SFG Rickettsia spp. in horses from Italy. Finding Rickettsia-positive horses suggests that they can contribute to the natural cycle of these bacteria as hosts for infected ticks. Equine illness related to rickettsia has never been described, therefore horses could respond immunologically to exposure to rickettsiae without developing clinical signs.

An experimental infection of horses with $R$. rickettsii demonstrated that the animals had no bacteremia, clinical, hematological, or blood biochemical alterations, but they had specific antibodies from 10 days to 2 years after infection [39].

During the present investigation, R. conorii, which belongs to the SFG, was used as an antigen for IFA. This pathogen, an agent of MSF disease, has been frequently found in Italy, as demonstrated by serological and molecular studies [33,35,40,41].

Horses resulting positive for rickettsiosis could have antibodies to $R$. conorii, as well as to other SFG Rickettsia spp. present in Italy, because IFA, even though considered the gold standard method for the serological diagnosis of rickettsiosis [42], is not able to differentiate between antibodies against the different SFG species [5].

Horses are largely employed in agonistic activity and are frequently maintained for recreational purposes, therefore, humans are highly exposed to the risk of being bitten by ticks previously fed on infected horses, as suggested by some authors who have considered human contact with horses as a risk factor for acquiring tick-borne lymphadenopathy (TIBOLA) caused by R. slovaca [43]. 
Detection of horses with antibodies to both A. phagocytophilum and SFG Rickettsia spp. confirms that the equine population, as well as human beings and other animals, may be affected by more arthropod-borne pathogens as consequence of the transmission by one tick harboring different microorganisms and/or more infected ticks. A. phagocytophilum, Borrelia burgdorferi sensu lato, Coxiella burnetii, and piroplasms have been demonstrated to be responsible for co-infections in clinically healthy and symptomatic horses $[19,20,22]$. Further studies could be useful to investigate if rickettsiae may complicate equine clinical forms when involved in co-infections.

\section{Material and Methods}

\subsection{Animals}

From January 2013 to December 2018, peripheral whole blood samples were collected from 479 grazing horses. Animals were actively racing and lived in various farms and horse centres located in lowland and hilly areas of Central Italy; they did not show clinical signs and were not under antibiotic treatment. Breeders and owners reported previous tick exposure.

Whole blood samples (about $10 \mathrm{~mL}$ ), drawn from the right or left jugular vein, were centrifuged at $1500 \times \mathrm{g}$ for $15 \mathrm{~min}$, and the sera were collected and immediately tested or stored at $-20^{\circ} \mathrm{C}$.

\section{Ethical Statement}

The collection of blood samples was executed for other clinical exams as part of routine health care by collaborating veterinarians during clinical visits. All animals were treated with standard practices of animal care and no horses were submitted to blood collection for this study only. However, in all cases, informed consent was obtained from the owners.

\subsection{Serological Analyses}

The indirect immunofluorescence antibody test (IFA) was executed on IFA slides prepared with Anaplasma phagocytophilum and Rickettsia conorii (Fuller Laboratories Fullerton, California, USA) antigens, respectively.

Blood sera were diluted 1:40 and 1:64 in phosphate-buffered saline (PBS, pH 7.2), considered cut-off values for A. phagocytophilum and Rickettsia spp., respectively, as reported in previous studies [13,44]. The test was executed employing a rabbit fluorescein isothiocyanate-conjugated anti-horse IgG (Sigma-Aldrich, Milano, Italy) diluted 1:30 in Evans Blue (Sigma-Aldrich) solution and following the manufacturer's procedure. Samples scored positive were two-fold serially diluted to determine the endpoint titre.

\subsection{Statistical Analysis}

Statistical evaluation was carried out by the $\chi^{2}$ test to analyze the results of serological tests in relationship to the years in which samples were collected. Values of $P<0.05$ were considered significant.

\section{Conclusions}

Grazing horses living in central Italy seem to be frequently exposed to ticks, and consequently to pathogens transmitted by these hematophagous vectors. The present results confirm the spreading of A. phagocytophilum in the investigated geographic area, where the bacterium has been previously found in various animal populations.

Moreover, horses scored positive to SFG Rickettsia spp. suggest that they can be infected by this microorganism, too, even though they do not develop disease.

In all cases, infected horses may be involved in the epidemiological cycle of $A$. phagcoytophilum and SFG species, as $R$. conorii and other rickettsiae that were considered non-pathogenic for decades and now are associated with human infections. 
Considering that the spreading of tick-borne diseases is a growing concern, and in light of the One-Health concept, it is necessary to increase the surveillance of these infections in animals, not only pets but also horses, that have frequent contact with humans.

Funding: This research received no external funding.

Conflicts of Interest: The author declares no conflict of interest.

\section{References}

1. Dumler, J.S.; Barbet, A.F.; Bekker, C.P.J; Dasch, G.A.; Palmer, G.H.; Ray, S.C.; Rikihisa, Y.; Rurangirwa, F.R. Reorganization of genera in the families Rickettsiaceae and Anaplasmataceae in the order Rickettsiales: Unification of some species of Ehrlichia with Anaplasma, Cowdria with Ehrlichia, and Ehrlichia with Neorickettsia, descriptions of six new species combinations and designation of Ehrlichia equi and "HGE agent" as subjective synonyms of Ehrlichia phagocytophila. Int. J. Syst. Evol. Microbiol. 2001, 51, 2145-2165.

2. Stuen, S.; Granquist, E.G.; Silaghi, C. Anaplasma phagocytophilum-A wide spread multi-host pathogen with highly adaptive strategies. Front. Cell. Infect. Microbiol. 2013, 3, 1-33. [CrossRef]

3. Bakken, J.B.; Dumler, J.S. Human granulocytic anaplasmosis. Infect. Dis. Clin. N. Am. 2015, 29, 341-355. [CrossRef]

4. Franzén, P.; Aspan, A.; Egenvall, A.; Gunnarsson, A.; Aberg, L.; Pringle, J. Acute clinical, hematologic, serologic, and polymerase chain reaction findings in horses experimentally infected with a European strain of Anaplasma phagocytophilum. J. Vet. Intern. Med. 2005, 9, 232-239. [CrossRef]

5. Brouqui, P.; Parola, P.; Fournier, P.E.; Raoult, D. Spotted fever rickettsioses in southern and Eastern Europe. FEMS Immunol. Med. Microbiol. 2007, 49, 2-12. [CrossRef]

6. Vescio, M.F.; Piras, M.A.; Ciccozzi, M.; Carai, A.; Farchi, F.; Maroli, M.; Mura, M.S.; Rezza, G.; MSF Study Group. Socio-demographic and climatic factors as correlates of Mediterranean spotted fever (MSF) in northern Sardinia. Am. J. Trop. Med. Hyg. 2008, 78, 318-320. [CrossRef]

7. Beninati, T.; Lo, N.; Noda, H.; Esposito, F.; Rizzoli, A.; Favia, G.; Genchi, C. First detection of spotted fever group rickettsiae in Ixodes ricinus from Italy. Emerg. Infect. Dis. 2002, 8, 983-986. [CrossRef]

8. Vitale, G.; Mansuelo, S.; Rolain, J.M.; Raoult, D. Rickettsia massiliae human isolation. Emerg. Infect. Dis. 2006, 12, 174-175. [CrossRef]

9. Floris, R.; Yurtman, A.N.; Margoni, E.F;; Mignozzi, K.; Boemo, B.; Altobelli, A.; Cinco, M. Detection and identification of Rickettsia species in the northeast of Italy. Vector Borne Zoonotic Dis. 2008, 8, 777-782. [CrossRef]

10. Mura, A.; Masala, G.; Tola, S.; Satta, G.; Fois, F.; Piras, P.; Rolain, J.M.; Raoult, D.; Parola, P. First direct detection of rickettsial pathogens and a new rickettsia, "Candidatus Rickettsia barbariae", in ticks from Sardinia, Italy. Clin. Microbiol. Infect. 2008, 14, 1028-1033.

11. Selmi, M.; Martello, E.; Bertolotti, L.; Bisanzio, D.; Tomassone, L. Rickettsia slovaca and Rickettsia raoultii in Dermacentor marginatus ticks collected on wild boars in Tuscany, Italy. J. Med. Entomol. 2009, 46, 1490-1493. [CrossRef]

12. Trotta, M.; Nicetto, M.; Fogliazza, A.; Montarsi, F.; Caldin, M.; Furlanello, T.; Solano-Gallego, L. Detection of Leishmania infantum, Babesia canis, and rickettsiae in ticks removed from dogs living in Italy. Ticks Tick Borne Dis. 2012, 3, 294-297. [CrossRef]

13. Elfving, K.; Malmsten, J.; Dalin, A.M.; Nilsson, K. Serological and molecular prevalence of Rickettsia helvetica and Anaplasma phagocytophilum in wild cervids and domestic mammals in the Central parts of Sweden. Vector Borne Zoonotic Dis. 2015, 15, 529-534. [CrossRef]

14. Skotarczak, B.; Wodecka, B.; Rymaszewska, A.; Adamska, M. Molecular evidence for bacterial pathogens in Ixodes ricinus ticks infesting Shetland ponies. Exp. Appl. Acarol. 2016, 69, 179-189. [CrossRef]

15. Parola, P.; Paddock, C.D.; Socolovschi, C.; Labruna, M.B.; Mediannikov, O.; Kernif, T.; Abdad, M.Y.; Stenos, J.; Bitam, I.; Fournier, P.E.; et al. Update on tick-borne rickettsioses around the world: A geographic approach. Clin. Microbiol. Rev. 2013, 26, 657-702, Erratum in: Clin. Microbiol. Rev. 2014, 27, 166. [CrossRef] 
16. Alberti, A.; Zobba, R.; Chessa, B.; Addis, M.F.; Sparagano, O.; Pinna Parpaglia, M.L.; Cubeddu, T.; Pintori GPittau, M. Equine and canine Anaplasma phagocytophilum strains isolated on the island of Sardinia (Italy) are phylogenetically related to pathogenic strains from the United States. Appl. Environ. Microbiol. 2005, 71, 6418-6422. [CrossRef]

17. Passamonti, F.; Veronesi, F.; Cappelli, K.; Capomaccio, S.; Coppola, G.; Marenzoni, M.L.; Piergili Fioretti, D.; Verini Supplizi, A.; Coletti, M. Anaplasma phagocytophilum in horses and tick: A preliminary survey of central Italy. Comp. Immunol. Microbiol. Infect. Dis. 2010, 33, 73-83. [CrossRef]

18. Giudice, E.; Giannetto, C.; Furco, V.; Alongi, A.; Torina, A. Anaplasma phagocytophilum seroprevalence in equids: A survey in Sicily (Italy). Parasitol. Res. 2012, 111, 951-955. [CrossRef]

19. Laus, F.; Veronesi, F.; Passamonti, F.; Paggi, E.; Cerquetella, M.; Hyatt, D.; Tesei, B.; Fioretti, D.P. Prevalence of tick borne pathogens in horses from Italy. J. Vet. Med. Sci. 2013, 75, 715-720. [CrossRef]

20. Ebani, V.V.; Nardoni, S.; Bertelloni, F.; Rocchigiani, G.; Mancianti, F. Tick-borne infections in horses from Tuscany, Italy. J. Equine Vet. Sci. 2015, 35, 290-294. [CrossRef]

21. Leblond, A.; Pradier, S.; Pitel, P.H.; Fortier, G.; Boireau, P.; Chadoeuf, J.; Sabatier, P. An epidemiological survey of equine anaplasmosis (Anaplasma phagocytophilum) in southern France. Rev. Sci. Tech. 2005, 24, 899-908. [CrossRef]

22. Ribeiro, A.J.; Cardoso, L.; Maia, J.M.; Coutinho, T.; Cotovio, M. Prevalence of Theileria equi, Babesia caballi and Anaplasma phagocytophilum in horses from the north of Portugal. Parasitol. Res. 2013, 112, 2611. [CrossRef]

23. Tsachev, I.; Pantchev, N.; Marutsov, P.; Petrov, V.; Gundasheva, D.; Baymakova, M. Serological evidence of Borrelia burgdorferi, Anaplasma phagocytophilum and Ehrlichia spp. infections on horses from Southeastern Bulgaria. Vector Borne Zoonotic Dis. 2018, 18, 588-594. [CrossRef]

24. Hulínská, D.; Langøová, K.; Pejèoch, M.; Pavlásek, I. Detection of Anaplasma phagocytophilum in animals by real-time polymerase chain reaction. APMIS 2004, 112, 239-247. [CrossRef]

25. Butler, C.M.; Nijhof, A.M.; Jongejan, F.; Van der Kolk, J.H. Anaplasma phagocytophilum infection in horses in the Netherlands. Vet. Rec. 2008, 162, 216-217. [CrossRef]

26. Slivinska, K.; Vichová, B.; Wersko, J.; Szewczyk, T.; Wróblewski, Z.; Pet'ko, B.; Ragač, O.; Demeshkant, V.; Karbowiak, G. Molecular surveillance of Theileria equi and Anaplasma phagocytophilum infections in horses from Ukraine, Poland and Slovakia. Vet. Parasitol. 2016, 215, 35-37. [CrossRef]

27. Rosso, F.; Tagliapietra, V.; Baráková, I.; Derdáková, M.; Konečny, A.; Hauffe, H.C.; Rizzoli, A. Prevalence and genetic variability of Anaplasma phagocytophilum in wild rodents from the Italian Alps. Parasites Vectors 2017, 10, 293. [CrossRef]

28. De Arcangeli, S.; Balboni, A.; Serafini, F.; Battilani, M.; Dondi, F. Anaplasma phagocytophilum infection in thrombocytopenic dogs. Vet. Ital. 2018, 54, 73-78.

29. Ebani, V.V.; Rocchigiani, G.; Bertelloni, F.; Nardoni, S.; Leoni, A.; Nicoloso, S.; Mancianti, F. Molecular survey on the presence of zoonotic arthropod-borne pathogens in wild red deer (Cervus elaphus). Comp. Immunol. Microbiol. 2016, 47, 77-80. [CrossRef]

30. Ebani, V.V.; Rocchigiani, G.; Nardoni, S.; Bertelloni, F.; Vasta, V.; Papini, R.A.; Verin, R.; Poli, A.; Mancianti, F. Molecular detection of tick-borne pathogens in wild red foxes (Vulpes vulpes) from Central Italy. Acta Trop. 2017, 172, 197-200. [CrossRef]

31. Aureli, S.; Foley, J.E.; Galuppi, R.; Rejmanek, D.; Bonoli, C.; Tampieri, M.P. Anaplasma phagocytophilum in ticks from parks in the Emilia-Romagna region of northern Italy. Vet. Ital. 2012, 48, 413-423. [PubMed]

32. Pusterla, N.; Madigan, J.E. Anaplasma Phagocytophila. In Equine Infectious Disease; Sellon, C.D., Long, M.T., Eds.; Saunders: St Louis, MO, USA, 2007; pp. 354-357.

33. Gomez-Barroso, D.; Vescio, M.F.; Bella, A.; Ciervo, A.; Busani, L.; Rizzo, C.; Rezza, G.; Pezzotti, P. Mediterranean spotted fever rickettsiosis in Italy, 2001-2015: Spatio-temporal distribution based on hospitalization records. Ticks Tick-Borne Dis. 2019, 10, 43-50. [CrossRef] [PubMed]

34. Solano-Gallego, L.; Trotta, M.; Caldin, M.; Furlanello, T. Molecular survey of Rickettsia spp. in sick dogs in Italy. Zoonoses Public Health 2008, 55, 521-525. [PubMed]

35. Solano-Gallego, L.; Caprì, A.; Pennisi, M.G.; Caldin, M.; Furlanello, T.; Trotta, M. Acute febrile illness is associated with Rickettsia spp. infection in dogs. Parasites Vectors 2015, 8, 216. [CrossRef] [PubMed]

36. Riveros-Pinilla, D.A.; Acevedo, G.L.; Londoño, A.F.; Gongóra, A. Antibodies against spotted fever group Rickettsia sp. in horses of the Colombian Orinoquia. Rev. MVZ Cordoba 2015, 20, 5004-5013. [CrossRef] 
37. Souza, C.E.; Bonato Camargo, L.; Pinter, A.; Donalisio, M.R. High seroprevalence for Rickettsia rickettsii in equine suggests risk of human infection in silent areas for the Brazilian Spotted Fever. PLoS ONE 2016, 11, e0153303. [CrossRef] [PubMed]

38. Filho, E.F.A.; Costa, F.B.; Moraes-Filho, J.; Gomes dos Santos, A.C.; Lopes do Vale, T.; Pereira da Costa, A.; Barbosa Silva, A.; Labruna, M.B.; de Maria Seabra Nogueira, R. Exposure of Baixadeiro horses ro Rickettsia spp. and to ticks infected by Rickettsia amblyommatis in the Baixada Maranhense micro-region, Maranhão, Brazil. Cienc. Rural 2018, 48, 1-7.

39. Ueno, T.E.H.; Costa, F.B.; Moraes-Filho, J.; Agostinho, W.C.; Fernandes, W.R.; Labruna, M.B. Experimental infection of horses with Rickettsia rickettsia. Parasites Vectors 2016, 9, 499. [CrossRef] [PubMed]

40. Vitaliti, G.; Falsaperla, R.; Lubrano, R.; Rapisarda, V.; Cocuzza, S.; Nunnari, G.; Pavone, P. Incidence of Mediterranean spotted fever in Sicilian children: A clinical-epidemiological observational retrospective study from 1987 to 2010. Int. J. Infect. Dis. 2015, 31, 35-40. [CrossRef] [PubMed]

41. Vascellari, M.; Ravagnan, S.; Carminato, A.; Cazzin, S.; Carli, E.; Da Rold, G.; Lucchese, L.; Natale, A.; Otranto, D.; Capelli, G. Exposure to vector-borne pathogens in candidate blood donor and free-roaming dogs of northeast Italy. Parasites Vectors 2016, 9, 369. [CrossRef]

42. La Scola, B.; Raoult, D. Laboratory diagnosis of rickettsioses: Current approaches to the diagnosis of old and new rickettsial diseases. J. Clin. Microbiol. 1997, 35, 2715-2727. [PubMed]

43. Lakos, A.; Kőrösi, A.; Földvári, G. Contact with horses is a risk factor for tick-borne lymphadenopathy (TIBOLA): A case control study. Wien. Klin. Wochenschr. 2012, 124, 611-617. [CrossRef] [PubMed]

44. Franzen, P.; Berg, A.L.; Aspan, A.; Gunnarsson, A.; Pringle, J. Death of a horse infected experimentally with Anaplasma phagocytophilum. Vet. Rec. 2007, 160, 122-125. [CrossRef] [PubMed]

(C) 2019 by the author. Licensee MDPI, Basel, Switzerland. This article is an open access article distributed under the terms and conditions of the Creative Commons Attribution (CC BY) license (http://creativecommons.org/licenses/by/4.0/). 